\title{
TIPIFICANDO A RACIONALIDADE JURÍDICA
}

\author{
Lucas Voigt Noernberg* \\ Paulo Ricardo Opuszka ${ }^{* *}$
}

\begin{abstract}
RESUMO
A racionalidade jurídica enquanto um dos pressupostos ideológicos do direito moderno busca a legitimação do direito pela razão científica. Essa racionalidade se apresenta neutra e anistórica quando na verdade representa um fenômeno, o direito moderno. Direito moderno o qual é formado em processos históricos definidos, sendo eles a modernidade e o capitalismo. Através de uma análise crítica o presente trabalho pretende utilizar a sociologia weberiana para tipificar essa racionalidade por meio das relações criadoras e/ou decorrentes da mesma.
\end{abstract}

PALAVRA-CHAVE: Racionalidade jurídica. Teoria crítica do direito. Dominação. Ciência. Capitalismo.

\begin{abstract}
Legal rationality as one of the ideological presuppositions of modern law seeks the legitimation of law by scientific reason. This rationality presents itself neutral and anistórica when in fact it represents a phenomenon, modern law. Modern law which is formed in defined historical processes, being modernity and capitalism. Through a critical analysis the present work intends to use Weberian sociology to typify this rationality from the creative relations and/or arising from it.
\end{abstract}

KEY-WORD: Legal rationality. Critical theory of law. Domination. Science. Capitalism.

\footnotetext{
Advogado. Pós-Graduando a nível de especialização em Direito do Trabalho e Processo do Trabalho, pela Escola Brasileira de Direito Aplicado.

** Doutor em Direito pela Universidade Federal do Paraná. Professor Permanente do Programa de Pós-Graduação em Direito da Universidade Federal do Paraná.
} 


\section{1 - OS TRÊS PRESSUPOSTOS IDEOLÓGICOS DO DIREITO}

A presente análise procura se debruçar sobre o pressuposto ideológico da racionalidade jurídica, procurando através da Teoria Crítica do Direito desmistificar a pretensão de neutralidade e anistoricidade do pressuposto, utilizando para tal, dentre outros marcos teóricos a sociologia de Max Weber, mais especificamente sua tipologia da dominação.

Estudar a racionalidade jurídica se mostra pertinente e necessário no momento em que o direito contemporâneo não superou as perspectivas paradigmáticas advindas da formulação moderna do direito, as quais ainda se concebem no tripé ideológico da unicidade ou monismo e da estatalidade que junto com a racionalidade estruturam a dogmática do direito (COELHO, 2003).

Distintamente da ordem jurídica feudal, pluralista e consuetudinária, o direito da sociedade moderna, além de encontrar no Estado sua fonte nuclear, constituiu-se em um sistema único de normas jurídicas integradas, produzidas para regular, em determinado espaço e tempo, os interesses de uma comunidade nacionalmente organizada. Este direito nacional é instrumentalizado por regras neutras positivamente postas, só podendo ser produzido através de órgãos e de instituições reconhecidos ou oficializados pelo Estado, se caracterizando assim o princípio da unicidade ou monismo jurídico pelo reconhecimento exclusivo do direito estatal, importando fundamentalmente em deslegitimar e suprimir qualquer forma de direito que não a oficial. (WOLKMER, 2001).

O princípio da estatalidade se refere ao Estado como personificação do direito ou como criador do direito, excluindo toda e qualquer norma jurídica fora do Estado (REALE, 1984, apud, WOLKMER, 2001), importando assim além da unificação nacional do direito, fazer imperar através de sua força coativa a lei estatal em face de práticas normativas pluralistas.

Já a racionalidade jurídica se apresenta como fonte de legitimidade tanto da estatalidade quando do monismo consistindo na crença em que o direito é em si mesmo racional, imputando a manifestação do ser jurídico como uma estrutura, cujos elementos se articulam de acordo com um logos que se explica e se demonstra pelos princípios da lógica formal. Em outras palavras, não se cogita 
de que, sendo o homem dotado de razão, arruma ele os elementos da estrutura jurídica em acordo com a sua própria racionalidade subjetiva; o que o senso comum internaliza é que o próprio direito é racionalmente articulado, e, como tal sua racionalidade imanente impõe-se à experiência teórica e prática, e assim, o direito é definido como ordem, ordenamento ou sistema, significantes cuja conotação envolve o conceito de racionalidade tal como a ideologia a construiu: uma racionalidade, fundamentada nos princípios da lógica formal (COELHO, 2003).

O princípio da racionalidade tem uma conexão direta com o da estatalidade, pela lógica de que se o Estado é a única fonte do direito, ou possui a primazia deste, os homens enquanto seres racionais não se deixariam guiar por seres ou mediante meios irracionais (COELHO, 2003).

Conceituados os pressupostos ideológicos do direito moderno é necessária a localização da racionalidade jurídica, objeto desta análise, junto aos processos históricos que lhe darão formatação.

\section{2 - COORDENADAS HISTÓRICAS}

É imprescindível a localização histórica da racionalidade jurídica, a qual tem sua formatação moderna concebida no entrecruzar de dois processos históricos, o projeto da modernidade e o capitalismo.

O projeto da modernidade previa a racionalização da vida coletiva e individual, pressupondo assim garantir a harmonização de valores socialmente colidentes como igualdade e liberdade. Essa busca da racionalização da vida se dará nas três lógicas de racionalidade que compõem o pilar emancipação, as lógicas weberianas da racionalidade estético-expressiva das artes e da literatura, a racionalidade cognitivo-instrumental da ciência e da tecnologia e a racionalidade moral-prática da ética e do direito (SANTOS, 2002). Essa expectativa de racionalização completa da vida é alcançada não na expectativa emancipadora da modernidade, mas em um dos entrecruzares deste projeto com o capitalismo.

O capitalismo transformou a ciência em sua principal força de produção, incentivando que nos tensionamentos entre os pilares da emancipação e da regulação ocorresse a hipercientificização da 
emancipação e a hipermercadorização da regulação (SANTOS, 2002).

Com a cientificização da emancipação ocorre uma lógica sobreposição das lógicas de racionalidade estético-expressiva e moral-prática pela racionalidade cognitivo-instrumental da ciência, de modo que antes a racionalidade proposta pela modernidade para emancipar se torna exclusivamente regulatória e como se verá acaba se tornado uma ferramenta de dominação imprescinde um momento especifico no entrecruzar de modernidade e do capitalismo.

Ainda perspectiva da hipercietificização do pilar da emancipação importa ressaltar que a lógica racional jurídica cede a lógica cientifica, sendo o direito transformado em direito estatal e cientifico, se submetendo a racionalidade cognitivo instrumental da ciência para que com a força coativa do estado se transformasse em um racionalizador social de segunda ordem da social, para garantir assim a ordem exigida pelo capitalismo que teve seu desenvolvimento ocorrido em um clima de caos social (SANTOS, 2002).

Nesse processo de busca da "boa ordem" necessária ao bom desenvolver do capitalismo, o direito é unificado e monopolizado pelo Estado e passa a fundamentar sua legitimidade na racionalidade, sendo em si racional.

O princípio da racionalidade se torna o principal fundamento da legitimidade do direito estatal e da ordem social de que ele pretende ser a representação real (COELHO, 2003). A racionalização do direito o torna adequado ao capitalismo quando se submete a racionalidade cientifica que está a serviço deste, o adequando ao sistema econômico e social e ao mesmo tempo reduzindo seu potencial emancipatório. A racionalização do direito bem como de toda a vida social não é despretensiosa. Eleita como a nova religião da humanidade e dotando discursivamente de neutralidade e legalidade o direito e o Estado, a racionalidade possui uma retórica de neutralidade de propósitos mas acaba por se revelar uma verdadeira forma de dominação (SANTOS, 2002).

De modo que a vida foi colonizada pela ciência, esta enquanto uma ferramenta de emancipação acabou por reduzir todo o processo histórico da modernidade em si mesma, e a ciência com sua racionalidade cognitivo-instrumental reinou absoluta, se tornando dogma. 


\section{3 - AS TIPOLOGIAS DA DOMINAÇÃO}

É possível encontrar em Max Weber uma tipologia da dominação, mas antes é necessário encontrar o que significa dominação. Para Julien Freund (2003) autor francês que trabalha a sociologia weberiana, o domínio segundo Weber é a manifestação concreta e empírica do poderio. Nesta senda o poderio se define como a oportunidade de um indivíduo de fazer triunfar no seio de uma relação social sua própria vontade contra resistências, e o domínio como a oportunidade de aí encontrar pessoas dispostas a obedecer à ordem que lhes é dada.

Ainda segundo Julien Freund (2003) o poder não é necessariamente político. O poder torna-se político quando a vontade se orienta significativamente em função de um agrupamento territorial, com vistas a realizar um fim, que só tem sentido pela existência desse agrupamento(nação).

Na lição de Raymond Aron (2008), para Max Weber a política é o conjunto das condutas humanas que comportam a dominação do homem pelo homem.

Voltando a Julien Freund (2003), na base de todo domínio político existe a relação fundamental do mando e da obediência. A obediência significa que os membros de uma unidade política agem como se fizessem do conteúdo da ordem a máxima de seu comportamento, simplesmente porque reconhecem formalmente sua necessidade, independentemente de sua própria opinião sobre o valor ou não-valor da ordem como tal. O mando é por sua natureza, fator de organização do agrupamento, ele se exerce em geral com base em uma organização fortemente estruturada, graças a presença de uma administração, de um aparelho permanente de constrangimento de regulamentos racionais etc., que são como garantias da continuidade da atividade política. Esta situação entretanto é característica apenas do Estado moderno e não da política em geral.

Muito importante para a presente análise salientar que a relação entre mando e a obediência faz com que todo o domínio seja exercido por um pequeno número, uma minoria que impõe, desta ou daquela maneira seu ponto de vista à maioria. Não existe governo de todos sobre todos, nem mesmo do maior número sobre o menor (FREUND, 2003). De modo que a relação de obediência e domínio 
revela automaticamente uma relação de desigualdade e não de funcionalidade ou qualquer outra retórica ideológica que se possa passar ao tentar legitimar uma relação de dominação. Obediência e domínio importam em uma sistemática relação de opressão.

Para Raymond Aron (2003) a diferença entre poder e dominação está em que, no primeiro caso, o comando não é necessariamente legítimo, nem a obediência necessariamente um dever; no segundo, a obediência se fundamenta no reconhecimento, por aqueles que obedecem, das ordens que lhe são dadas. As motivações da obediência permitirão portanto construir uma tipologia da dominação.

Max Weber (1999, p. 526) define os três tipos de dominação legitima como a dominação tradicional, carismática e a racionallegal, vindo a conceituá-las em sua obra Economia e Sociedade como: "dominação "tradicional", tal como a exerciam o patriarca e o príncipe patrimonial de antigamente. Segundo, a autoridade do dom de graça pessoal, extracotidiano (carisma): a entrega pessoal e a confiança pessoal em revelações, heroísmo ou outras qualidades de líder de um indivíduo: dominação, "carismática", tal como a exercem o profeta ou - na área política o príncipe guerreiro eleito ou o soberano plebiscitário, o grande demagogo e o chefe de um partido político. Por fim, a dominação, em virtude da "legalidade", da crença na validade de estatutos legais e da "competência" objetiva, fundamentada em regras racionalmente criadas, isto é, em virtude da disposição de obediência ao cumprimento de deveres fixados nos estatutos: uma dominação como a exercem o moderno "servidor público" e todos aqueles portadores de poder que com ele se parecem neste aspecto."

Julian Freund (2003) ensina que nenhum domínio se contenta com a obediência que não passa de submissão exterior pela razão, por oportunidade ou respeito; procura também despertar nos membros a fé em sua legitimidade, ou seja, transformar a disciplina em adesão à verdade que ele representa.

O domínio racional-legal pode ser reconhecido segundo Freund pelas seguintes características: todo direito, seja ele estabelecido por convenção ou por outorga, vale em virtude de um procedimento racional por finalidade ou por valor, ou pelos dois ao mesmo tempo. O conjunto das regras de direito constitui um mundo 
abstrato de prescrições técnicas ou de normas, a justiça consiste na aplicação das regas gerais aos casos particulares, enquanto a administração tem por objeto proteger os interesses nos limites da regra de direito, graças a órgãos instituídos para tal fim. Para o professor francês o domínio legal consiste um empreendimento contínuo de funções públicas instituídas por leis e distribuídas em competências diferenciadas. A aplicação desses inúmeros regulamentos exige uma equipe de funcionários qualificados, que não são donos de seus cargos, nem tampouco dos meios da administração. Por outro lado, são protegidos no exercício de suas funções por um estatuto. $\mathrm{O}$ procedimento administrativo repousa no princípio de documentos e fichários a serem conservados a época: todas as decisões, decretos e ordens de serviço são escritos. A mais típica forma do domínio legal é a burocracia (FREUND, 2003).

\section{4 - RACIONALIDADE JURÍDICA, TIPIFICANDO A DOMINAÇÃO}

Como no já citado entendimento de Raymond Aron (2008), as motivações da obediência permitirão o diagnóstico e uma tipificação da dominação.

A racionalidade constitui a motivação da obediência do homem e da sociedade moderna a ordem jurídica Estatal. A relação de dominação racional-legal se clarifica quando a legitimidade do Estado moderno se fundamenta nas retóricas de neutralidade e legalidade respaldadas no pressuposto de que o ordenamento jurídico que as sustenta é cientificamente racional.

O próprio Max Weber (1999, p. 529) vem definir o Estado moderno como uma relação de dominação em si, o conceituando como: "uma associação de dominação institucional, que dentro de determinado território pretendeu com êxito monopolizar a coação física legítima como meio da dominação e reuniu para este fim, nas mãos de seus dirigentes, os meios materiais de organização, depois de desapropriar todos os funcionários estamentais autônomos que antes dispunham, por direito próprio, destes meios e de colocar-se, ele próprio, em seu lugar, representado por seus dirigentes supremos."

O sociólogo alemão atribui o desenvolvimento desse Estado burocrático que administra e sentencia com base em um direito 
racionalmente estatuído ao desenvolvimento do capitalismo moderno. O capitalismo se baseia no cálculo e imprescinde de uma justiça e de uma administração que possam ser racionalmente calculadas por normas gerais e fixas. Segundo Weber (1999) o capitalismo só poderia surgir em locais como na Inglaterra, onde a elaboração prática do direito estava de fato nas mãos dos advogados, os quais, a mando de sua clientela, isto é, dos interessados capitalistas, criaram as formas apropriadas de negócios. Desse mesmo círculo procediam os juízes, que estavam obrigados a orientar-se por "precedentes", isto é, por esquemas previsíveis. O capitalismo só surgiria em outro cenário onde, como no Estado burocrático com suas leis racionais, o juiz é algo como um autômato de parágrafos, no qual se enfia em cima a documentação mais os custos e as taxas para que solte em baixo a sentença mais a motivação razoavelmente convincente, isto é, cujo funcionamento, de maneira geral, é calculável.

A dominação racional resulta da colonização da racionalidade cognitivo-instrumental da ciência sobre as outras racionalidades do pilar da emancipação como consequência e somado a transformação da ciência na principal força produtiva do capitalismo.

Mas como antevemos nesta análise, as relações de obediência e domínio sempre se dão de uma minoria sobre uma maioria. Quem seria a maioria dominante nesta relação de poder?

Assevera Luiz Fernando Coelho (2003) que a partir do momento em que o senso comum projeta sua própria razão, isto é, o modo como ela se manifesta subjetivamente nos seres humanos, sobre o direito objetivamente considerado, o princípio da racionalidade se erige em pressuposto ideológico: não é o jurista nem os sujeitos das relações jurídicas que são racionais, mas o próprio direito, em suas expressões normativas, ordenamentais e decisionais, é que é dotado de uma racionalidade imanente, a qual cabe ao jurista captar; dessa forma concretiza-se o processo sociopsicológico de inversão, cumprindo a ideologia uma de suas funções primordiais.

É perceptível que a retórica de neutralidade anistoricidade que se pretende com a racionalização do direito é constrangida pela ideia da racionalidade jurídica enquanto ideologia. A racionalidade enquanto fonte legitimadora do direito é um meio para o próprio fim, o direito racional (COELHO, 2003). Uma tautologia. 
Nesta senda importa a distinção que faz Weber entre o direito como atividade racional em relação a valores e a em relação a fins. A primeira pode ser considerada uma racionalidade absoluta, desenvolve-se em nome de uma convicção, eis que se refere valores, o quais são em si irracionais. A segunda, que envolve uma racionalidade relativa, é que procura os meios adequados à consecução de um objetivo, isto é, refere-se a uma racionalidade dos meios (WEBER, 1972). A racionalidade jurídica enquanto critério de validade revelasse uma racionalidade em ralação a fins quando a racionalização dos meios é o seu principal fim. Também não se pode deixar de notar que a racionalidade em relação a valores, enquanto desenvolvida em torno de uma convicção, não é totalmente estranha a racionalização do direito enquanto este tem como critério canônico a cientificização.

Max Horkheimer (2002) conceitua razão como subjetiva e objetiva, em seu entendimento define a razão subjetiva como uma razão que se relaciona com meios e fins, com a adequação de procedimentos ou propósitos mais ou menos tidos como certos e que se presumem auto-explicativos, tendo pouco importância se os propósitos são ou não racionais, sendo obrigatoriamente racionais no sentido subjetivo da autopreservação do indivíduo ou da comunidade. Já a razão objetiva é contrária a concepção subjetiva de razão quando se preocupa precipuamente com os fins. Segundo Horkheimer, objetivando desenvolver uma hierarquia ou sistema abrangente de todos os seres, os grandes sistemas filosóficos como Platão e Aristóteles, o escolaticismo e o idealismo alemão não focavam na mediação dos meios aos fins mas nos conceitos, como o de bem supremo ou destino humano para fixar os critérios de razão, se revelando um pensamento racional voltado aos fins.

Essa conceituação feita por Max Horkheimer acaba se entrelaçando com as concepções de racionalidade interna e externa encontradas em Luiz Fernando Coelho, a racionalidade interna concebe o direito como racional em si, e a externa, a aceitação racional da atividade produtora do direito, difusa no meio social como algo legítimo.

A razão objetiva encontrada em Horkheimer se revela no direito quando este, em sua racionalidade externa, baseia sua legitimidade no consenso de seus destinatários, destinatários esses que fundaram seu consenso na racionalidade, esse processo 
tautológico termina por revelar que a ordenação racional do direito acaba por ser na perspectiva externa o seu próprio fim, sendo assim a revelação da predominância da razão objetiva (COELHO, 2003).

A ideologia do direito enfatiza o momento interno do princípio da racionalidade, no intuito de revesti-lo de uma característica de realidade objetiva: como lei e como ordenamento jurídico. Este momento interno se manifesta de três formas: racionalidade normativa, racionalidade ordenamental e racionalidade decisional .

Ensina Luiz Fernando Coelho (2003) que a racionalidade normativa implica a concepção da norma jurídica como objetivamente racional; ela é então concebida como um dever-ser, onde o liame entre os dois termos dessa relação deôntica é racional. A racionalidade ordenamental implica na concepção do direito como ordem jurídica, um conjunto de normas cuja articulação interna é racional formando um sistema. O direito não é só somente norma racional mas um sistema normativo, sendo visto objetivamente racional nas articulações entre os elementos que o compõem, vigorando esta como a teoria dominante no senso comum.

A racionalidade decisional se fundamenta sobre a pretensão de neutralidade do julgador, sendo as decisões em especial as jurídicas, produzidas sem a interferência de fatores emocionais e outros que podem não ser reduzidos a razão, sendo a racionalidade das decisões fundadas em normas jurídicas a garantia de neutralidade do julgador.

A sistematização do direito não consegue e não pode dar conta de todas possibilidades de ações sociais, implicando assim na insuficiência do princípio da plenitude .

Essa insuficiência do princípio da plenitude, apesar de aparentemente contrapor a ideia de racionalidade ordenamental é prevista pela teoria tradicional do direito, podendo segundo esta vertente a lei ter lacunas mas o ordenamento não. A deficiência da lei será sanada no contencioso, mantendo a sentença a plenitude do ordenamento com o reconhecimento de um direito advindo do sistema jurídico, sendo este auto integrativo.

$\mathrm{O}$ direito e o Estado de direito se fundamentam na retórica da neutralidade e da legalidade (COELHO, 2003).

As retóricas da neutralidade e da legalidade se evidenciam no direito quando este em sua perspectiva interna se utiliza da racionalidade ordenamental, racionalidade normativa e racionalidade 
decisional, já conceituadas anteriormente, para tornar o ele mesmo um fenômeno dotado da racionalidade científica e por isso legítimo. Em sua perspectiva externa o direito se fundamenta no consenso de seus destinatários, os quais fundamentam o consenso na racionalidade do próprio direito.

O princípio da racionalidade acaba por construir um direito anistórico e atemporal (WOLKMER, 2001). Ela tem esses efeitos de anistoricidade e atemporalidade pois seus fundamentos são tautológicos e a racionalidade acaba se legitimando por si como se não fosse produto dos processos históricos que a originam.

O materialismo histórico de Karl Marx explica a história como sendo a da luta de classes, está sempre se dando na perspectiva do controle dos modos de produção do respectivo espaço tempo, com o fim do feudalismo surge a sociedade burguesa que não contrariando os processos históricos anteriores, estabeleceu novas classes e novas condições de opressão, se tornando hegemonicamente dominante (MARX; ENGELS, 2007).

Nesse sentido ensina Antonio Carlos Wolkmer (2001) que a burguesia, ao suplantar a nobreza e o clero, nos destroços do feudalismo, busca enquanto classe social detentora dos meios de produção adequar ao seu interesse uma ordem estatal fortalecida apta a legitimar seu sistema de normatividade. O capitalismo passa a forjar o projeto político centralizador e nada mais natural que enquanto regime sócio econômico monopolista ele impusesse uma adequada estrutura lógico formal a seus interesses. A ideologia de um Estado que encarna o próprio direito forja a concepção harmônica de mundo, e quando o direito é racionalizado pela ciência a legitimidade do sistema jurídico e do próprio Estado surge sobre as cores da neutralidade e da anistoricidade.

$\mathrm{Na}$ perspectiva de camuflagem da dominação a burguesia encontra na racionalidade uma ferramenta para impor sua dominação como acha nessa racionalidade científica um elemento além de legitimar a desigualdade, á torna natural.

O direito oficial é utilizado como instrumento de dominação dos grupos microssociais hegemônicos, os detentores do capital, devendo ser apresentado e absorvido como pleno, uno, racional, lógico, um sistema que tem a solução para todos os conflitos e que fora dele só haveria desordem e ruína social. (COELHO, 2003) 


\section{5 - CONSIDERAÇÕES FINAIS}

A racionalidade, por análise final além de fundamento de legitimidade da dominação através da ordem jurídica acaba sendo o meio onde se dá a própria dominação. Servindo a burguesia que controla o modo de produção capitalista, a racionalidade cognitivoinstrumental da ciência ao colonizar as demais lógicas da racionalidade demonstra que além de abandonar sua perspectiva emancipadora do projeto da modernidade se tornou uma ferramenta de opressão, o motivo da obediência, a causa da dominação.

O entrecruzar dos processos históricos do capitalismo e da modernidade, quando este super potencializa a ciência, acaba por pavimentar o caminho da burguesia como classe hegemônica e a relegar ao proletariado a tarefa de sustentar o sistema de produção capitalista às expensas da exploração de sua mão de obra.

Max Weber (1999) assevera que o Estado racional é o único em que pode florescer o capitalismo. Essa afirmativa é importante no sentido de confirmar que a pretensão de neutralidade e anistoricidade tanto do direito quanto do Estado se mostram retóricas quando o capitalismo imprescinde da sistemática racional para se manter hegemônico e a fonte de sua hegemonia por uma lógica simples nunca será a fonte de sua neutralidade.

A burguesia enquanto minoria dominante, surgiu entre os destroços do feudalismo e alcançou a hegemonia com o triunfo do capitalismo enquanto sistema de produção. Encontrou, no Estado moderno centralizado e no direito racional, a fonte da ordem que necessitava tanto para se manter hegemônica como para possibilitar o desenvolvimento de seu sistema econômico. A transformação da ciência em fator de produção e a guinada da emancipação moderna em direção ao duplo da regulação tornou o caminho para a dominação racional-legal um sentido obrigatório para a sociedade ocidental.

\section{BIBLIOGRAFIA}

ARON, Raymond. As etapas do pensamento sociológico. Tradução Sergio Bath. - 7. ed. - São Paulo: Martins Fontes, 2008. 
BOURDIEU, Pierre. O poder simbólico. Tradução Fernando Tomaz. 4. ed. Rio de Janeiro: Bertrand Brasil, 2001.

COELHO, Luiz Fernando. Teoria crítica do direito. 2. ed. Porto Alegre: Sergio Antonio Fabris Editor, 1991.

COELHO, Luiz Fernando. Teoria crítica do direito. 6. ed. Belo Horizonte: Del Rey, 2003.

FREUND, Julien. Sociologia de Max Weber. 5. ed. São Paulo:Forense Universitária. 2003.

HOBBES, Thomas. Leviatã ou matéria, forma e poder um de estado eclesiástico e civil. Traduzido por Alex Marins. São Paulo: Martin Claret, 2007.

HORKHEIMER, Max. Eclipse da razão. 7. ed. Tradução de Sebastião Uchoa Leite. São Paulo: Centauro. 2002.

MARX, Karl; ENGELS, F. Manifesto Comunista. Traduzido por Álvaro Pina. São Paulo: Boitempo. 2007.

MIALLE, Michel. Introdução crítica ao direito. 3. ed. Tradução Ana Prata. Lisboa: Estampa. 2005.

SANTOS, Boaventura de Souza. A crítica da razão indolente: contra o desperdício da experiência - 4. ed. São Paulo: Cortez, 2002.

SANTOS, Boaventura de Souza. Poderá o direito ser emancipatório? Revista Crítica de Ciências Sociais. Tradução de João Paulo Moreira. Disponível em https://rccs.revues.org/1180., acessado em 17 fev. 2016

WEBER, Max, Ciência e política: duas vocações. 2. ed. São Paulo:Cultrix, 1972.

WEBER, Max. Economia e sociedade: fundamentos da sociologia compreensiva. 2. vol. Traduzido por Regis Barbosa e Karen Elsabe Barbosa. Brasília: Universidade de Brasília, 1999.

WOLKMER, Antonio Carlos. Pluralismo jurídico. Fundamentos de uma nova cultura no Direito. 3. ed. São Paulo: Alfa Omega, 2001. 
